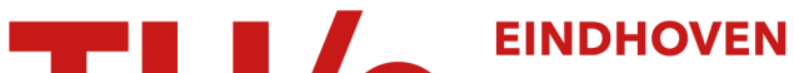 UNIVERSITY OF TECHNOLOGY
}

\section{Atomic hydrogen induced defect kinetics in amorphous silicon}

\section{Citation for published version (APA):}

Peeters, F. J. J., Zheng, J., Aarts, I. M. P., Pipino, A. C. R., Kessels, W. M. M., \& van de Sanden, M. C. M. (2017). Atomic hydrogen induced defect kinetics in amorphous silicon. Journal of Vacuum Science and Technology A: Vacuum, Surfaces, and Films, 35(5), [05C307]. https://doi.org/10.1116/1.4987152

DOI:

10.1116/1.4987152

Document status and date:

Published: 01/09/2017

\section{Document Version:}

Publisher's PDF, also known as Version of Record (includes final page, issue and volume numbers)

\section{Please check the document version of this publication:}

- A submitted manuscript is the version of the article upon submission and before peer-review. There can be important differences between the submitted version and the official published version of record. People interested in the research are advised to contact the author for the final version of the publication, or visit the $\mathrm{DOI}$ to the publisher's website.

- The final author version and the galley proof are versions of the publication after peer review.

- The final published version features the final layout of the paper including the volume, issue and page numbers.

Link to publication

\section{General rights}

Copyright and moral rights for the publications made accessible in the public portal are retained by the authors and/or other copyright owners and it is a condition of accessing publications that users recognise and abide by the legal requirements associated with these rights.

- Users may download and print one copy of any publication from the public portal for the purpose of private study or research.

- You may not further distribute the material or use it for any profit-making activity or commercial gain

- You may freely distribute the URL identifying the publication in the public portal.

If the publication is distributed under the terms of Article 25fa of the Dutch Copyright Act, indicated by the "Taverne" license above, please follow below link for the End User Agreement:

www.tue.nl/taverne

Take down policy

If you believe that this document breaches copyright please contact us at:

openaccess@tue.nl

providing details and we will investigate your claim. 


\section{Atomic hydrogen induced defect kinetics in amorphous silicon}

Floran J. J. PeetersJie Zhenglgor M. P. Aarts, Andrew C. R. Pipino, and Wilhelmus M. M. KesselsMauritius C. M. van de Sanden

Citation: Journal of Vacuum Science \& Technology A: Vacuum, Surfaces, and Films 35, 05C307 (2017); doi: 10.1116/1.4987152

View online: http://dx.doi.org/10.1116/1.4987152

View Table of Contents: http://avs.scitation.org/toc/jva/35/5

Published by the American Vacuum Society

\section{Articles you may be interested in}

Review Article: Recommended reading list of early publications on atomic layer deposition-Outcome of the "Virtual Project on the History of ALD"

Journal of Vacuum Science \& Technology A: Vacuum, Surfaces, and Films 35, 010801 (2016);

$10.1116 / 1.4971389$

Role of neutral transport in aspect ratio dependent plasma etching of three-dimensional features Journal of Vacuum Science \& Technology A: Vacuum, Surfaces, and Films 35, 05 C301 (2017); $10.1116 / 1.4973953$

Predicting synergy in atomic layer etching Journal of Vacuum Science \& Technology A: Vacuum, Surfaces, and Films 35, 05 C302 (2017); $10.1116 / 1.4979019$

Review Article: Reactions of fluorine atoms with silicon, revisited, again Journal of Vacuum Science \& Technology A: Vacuum, Surfaces, and Films 35, 05 C202 (2017); $10.1116 / 1.4983922$

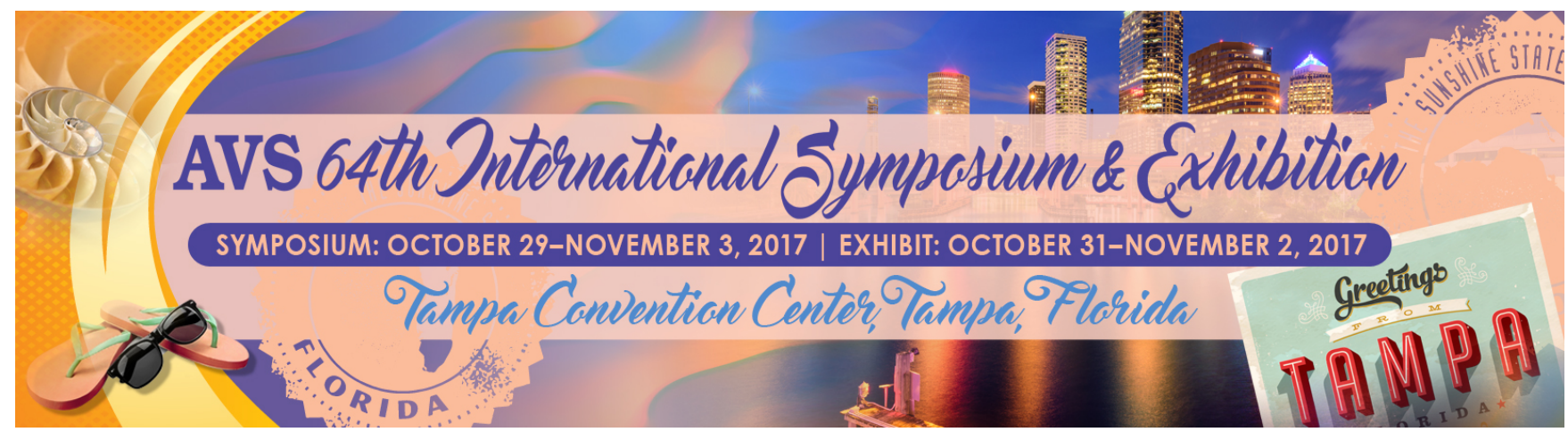




\title{
Atomic hydrogen induced defect kinetics in amorphous silicon
}

\author{
Floran J. J. Peeters \\ DIFFER - Dutch Institute for Fundamental Energy Research, De Zaale 20, 5612 AJ Eindhoven, \\ The Netherlands and Eindhoven Department of Applied Physics, University of Technology, \\ P.O. Box 513, NL-5600 MB Eindhoven, The Netherlands \\ Jie Zheng \\ Beijing National Laboratory for Molecular Sciences (BNLMS), College of Chemistry and Molecular \\ Engineering, Peking University, 5 Yiheyuan Road, Beijing 100871, People's Republic of China
}

Igor M. P. Aarts, Andrew C. R. Pipino, and Wilhelmus M. M. Kessels

Department of Applied Physics, Eindhoven University of Technology, P.O. Box 513, NL-5600 MB Eindhoven, The Netherlands

Mauritius C. M. van de Sanden ${ }^{\text {a) }}$

DIFFER—Dutch Institute for Fundamental Energy Research, De Zaale 20, 5612 AJ Eindhoven, The Netherlands and Department of Applied Physics, Eindhoven University of Technology, P.O. Box 513, NL-5600 MB Eindhoven, The Netherlands

(Received 2 April 2017; accepted 6 June 2017; published 29 June 2017)

\begin{abstract}
Near-infrared evanescent-wave cavity ring-down spectroscopy (CRDS) has been applied to study the defect evolution in an amorphous silicon (a-Si:H) thin film subjected to a directed beam of atomic $\mathrm{H}$ with a flux of $(0.4-2) \times 10^{14} \mathrm{~cm}^{-2} \mathrm{~s}^{-1}$. To this end, a $42 \pm 2 \mathrm{~nm}$ a-Si:H film was grown on the total internal reflection surface of a folded miniature optical resonator by hot-wire chemical vapor deposition. A fully reversible defect creation process is observed, with a nonlinear dependence on $\mathrm{H}$ flux, with a time resolution of $33 \mathrm{~ms}$ and a relative sensitivity of $10^{-7}$. Using polarizing optics, the CRDS signal was split into $s$ - and $p$-polarized components, which, combined with $E$ field calculations, provides depth sensitivity. Extensive kinetic modeling of the observed process is used to determine rate constants for the hydrogen-material interactions and defect formation in a$\mathrm{Si}: \mathrm{H}$, as well as revealing a high diffusion coefficient for atomic $\mathrm{H}$ on the order of $10^{-11} \mathrm{~cm}^{2} \mathrm{~s}^{-1}$. A novel reaction pathway is proposed, whereby $\mathrm{H}$ inserted into weak $\mathrm{Si}-\mathrm{Si}$ bonds recombines with mobile $\mathrm{H}$, resulting in a limited penetration depth for atomic $\mathrm{H}$ from the gas-phase on the order of 10-15 nm. @ 2017 American Vacuum Society. [http://dx.doi.org/10.1116/1.4987152]
\end{abstract}

\section{INTRODUCTION}

This work demonstrates the use of a monolithic optical resonator to detect defect states in thin films during exposure to a directed atomic beam, as well as introducing a physical model describing the results. The thin film chosen is hydrogenated amorphous silicon (a-Si:H) grown by hot-wire chemical vapor deposition (HW-CVD). Hydrogenated amorphous silicon has received considerable attention in the field of plasma processing due to its ubiquitous uses in electronic and optoelectronic devices. The interaction of atomic hydrogen with a-Si:H plays a crucial role in both the film growth ${ }^{1}$ and the reversible lightinduced degradation known as the Staebler-Wronski (SW) effect. $^{2}$ During growth, hydrogen is required to minimize the dangling bond defect density and is known to induce disorderto-order structural transitions in the material. ${ }^{3-7}$ In the SW effect, redistributions of small amounts of hydrogen liberated by photons into metastable configurations are commonly attributed as the source of electronic degradation. ${ }^{8-11}$ However, the exact mechanism behind the $\mathrm{SW}$ effect is still unknown. ${ }^{12-14}$

Over the years, numerous surface science studies have been devoted to crystalline silicon (c-Si), with its welldefined reconstructed surfaces. ${ }^{15-19}$ Initially, it was found that the abstraction and adsorption reactions by atomic $\mathrm{H}$

${ }^{a)}$ Electronic mail: m.c.m.v.d.sanden@tue.nl followed Eley-Rideal or hot precursor reaction schemes, ${ }^{19}$ respectively. However, Küppers and coworkers showed that $\mathrm{H}$ can also be abstracted through indirect pathways, ${ }^{16}$ while Flowers et al. ${ }^{17}$ and later Inanaga et al..$^{20}$ showed a quasiequilibrium model of surface species should be used to explain the uptake kinetics more precisely. In principle, the experiments on $\mathrm{c}-\mathrm{Si}$ can provide qualitative understanding of the kinetics of hydrogen interacting with a-Si:H. However, the amorphous nature of the $\mathrm{Si}$ thin films complicates the interpretation of reaction mechanisms considerably. Several in situ experiments have been carried out to establish the interaction of atomic $\mathrm{H}$ with a-Si: $\mathrm{H}$, including experiments based on nuclear magnetic resonance, ${ }^{21}$ hydrogen effusion, ${ }^{22}$ (spectroscopic) ellipsometry, ${ }^{23-25}$ and infrared (IR) absorption spectroscopy. ${ }^{26,27}$ Although important insight into the interaction of $\mathrm{H}$ with a-Si:H was obtained, detailed insight into the reaction kinetics of $\mathrm{H}$ and its relation with defect density was not obtained. Because most diagnostics used are based on the detection of hydrogen species, the interpretation of these kinds of experiments can be complicated due to the fact that a-Si:H contains a large amount of bulk hydrogen, making it difficult to distinguish the interaction of atomic $\mathrm{H}$ with a-Si:H. To obtain a full understanding of the interaction of atomic $\mathrm{H}$ with a-Si:H, particularly with respect to its role in the creation and passivation of defects, it is beneficial to 
probe the defect density, preferentially in situ and during hydrogen treatment.

Monitoring the defects also allows direct determination of the mobile hydrogen diffusion coefficient, as opposed to the effective diffusion coefficient obtained from SIMS studies on deuterium treated a-Si:H films. ${ }^{23-28}$ Such a measurement of the mobile hydrogen diffusion coefficient can set boundaries to certain SW models. Das et al. have reported on in situ electron spin resonance experiments where a-Si:H films were exposed to a flux of atomic hydrogen in the range of $10^{15}-10^{17} \mathrm{~cm}^{2} \mathrm{~s}^{-1} \cdot{ }^{34-36}$ It was observed that $\mathrm{H}$ dosing induces up to $4 \times 10^{13} \mathrm{~cm}^{-2}$ additional subsurface dangling bonds, dependent on film thickness, but independent of the flux for their conditions, which reversibly decay after the flux is terminated. From the observed penetration depth of dangling bond formation, a high diffusion coefficient $\left(>10^{-10} \mathrm{~cm}^{2} \mathrm{~s}^{-1}\right)$ for atomic $\mathrm{H}$ in a-Si:H was derived. However, their model to account for dangling bond creation is not validated in detail due to the limited time resolution of the ESR setup of up to $84 \mathrm{~s}^{36}$

Silicon dangling bonds can also be detected by near-IR absorption spectroscopy, i.e., by probing subgap defect states. ${ }^{37-40}$ In this paper, we present results of low flux atomic hydrogen dosing $\left(4-20 \times 10^{13} \mathrm{~cm}^{2} \mathrm{~s}^{-1}\right)$ of a $42 \pm 2 \mathrm{~nm}$ a-Si:H film measured by evanescent wave cavity ring-down spectroscopy (EW-CRDS) employing a monolithic optical resonator. ${ }^{41}$ This technique allows for real-time monitoring of the defect density with a time-resolution of $33 \mathrm{~ms}$ and a sensitivity of $10^{-7}$, with additional information provided by the $s$ - and $p$-polarization anisotropy, as demonstrated by previous experiments on the absolute dangling bond density during growth of $a$-Si:H (Ref. 38) and the characterization of a quasi-ice monolayer. ${ }^{42}$ Another clear advantage of CRDS is that absolute losses can be determined from the ring-down time without the need for calibration.

Our experimental results have sufficient time resolution to apply full kinetic modeling, while the polarization anisotropy allows for depth profiling of the defect density. We will show that additional, self-healing, defects are formed below the surface of the film by low incident atomic $\mathrm{H}$ fluxes and propose a kinetic model that accurately describes the kinetics of atomic $\mathrm{H}$ in the subsurface of a-Si:H. We conclude that the penetration depth of atomic $\mathrm{H}$ is limited by the formation of $\mathrm{H}_{2}$ at shallow trapping sites in the a-Si:H network, with a high diffusion coefficient of atomic $\mathrm{H}$ resulting from the absence of deep trapping sites.

In Sec. II, experimental details are presented including the deposition setup, sample preparation, atomic $\mathrm{H}$ source, folded resonator, and optical system, as well as spectroscopic ellipsometry (SE) and infrared spectroscopy experiments providing data complementary to the EW-CRDS results. In Secs. III A and III B, the H-dosing data and the extraction of defect density is addressed and a full model presented to account for the EW-CRDS results. In Sec. III C, the key observations are summarized and $\mathrm{H}$ reaction mechanisms in a-Si:H are discussed in light of these results.

\section{EXPERIMENT}

\section{A. UHV setup}

A schematic overview of the ultrahigh vacuum (UHV) setup is given in Fig. 1(a). The UHV setup consists of two stainless steel vacuum chambers (base-pressure $<10^{-9}$ mbar) that are separated by a flange that holds the folded resonator as a substrate. One chamber contains the sources for deposition and hydrogen dosing, and the other chamber contains a heater (Advanced Ceramics Corporation, Boralectric $^{\text {TM }}$ heater model HTR 1002, $1440 \mathrm{~W}$ ) for substrate heating and provides optical access to the folded resonator. The substrate temperature is actively controlled by a feedback loop using a thermocouple mounted close to the resonator. Deposition of a-Si:H on the total internal reflection (TIR) surface of the resonator takes place by the decomposition of purified silane $\left(\mathrm{SiH}_{4}\right.$, Praxair, purity $>99.995 \%$, delivered by a mass flow controller) on a hot coiled tungsten filament with a diameter $0.45 \mathrm{~mm}$. A quantified atomic hydrogen flux can be delivered to the substrate by an atomic $\mathrm{H}$ source described in more detail below. Both the hot filament and the $\mathrm{H}$ source are mounted on linear translators such that the distance between these sources and the substrate can be varied. An automated stainless steel shutter protects the substrate during startup of the sources and provides the opportunity for fast on-and-off switching of the radical fluxes to the TIR surface of the folded resonator.

(a)
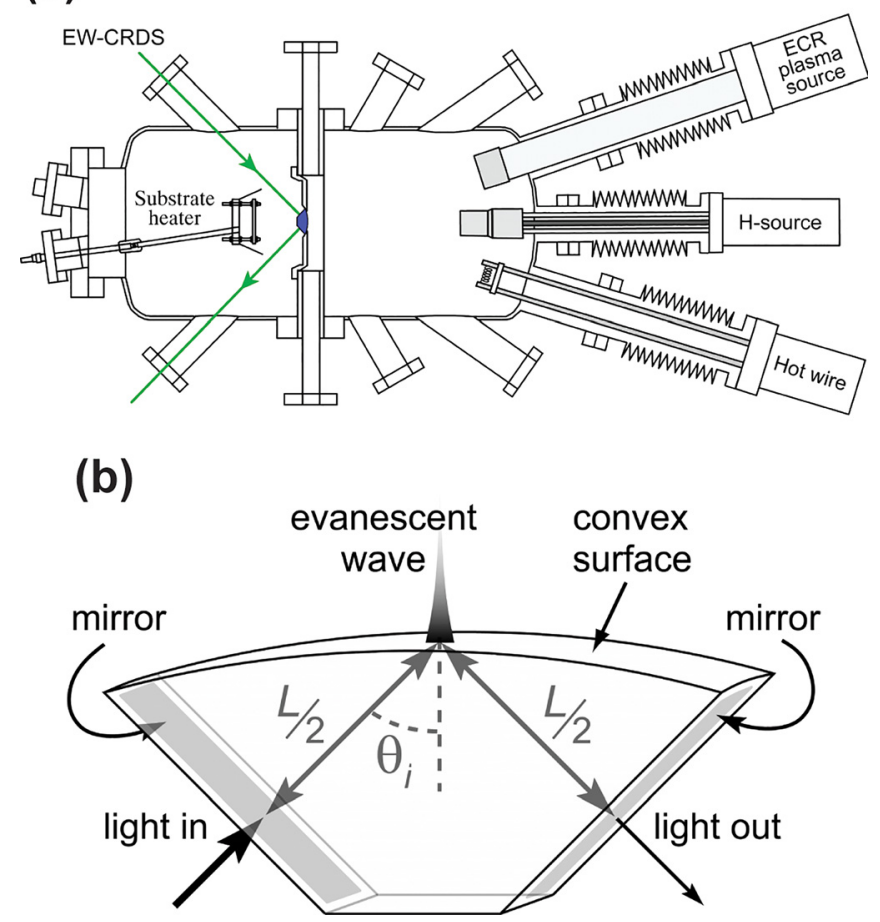

FIG. 1. (Color online) (a) UHV setup with folded cavity as substrate. (b) The monolithic folded resonator showing the two planar, high reflectivity coated (>99.998\%) dielectric mirrors, which is used to detect changes in the subgap absorption at $1200 \mathrm{~nm}$ of a $42 \pm 2 \mathrm{~nm}$ a-Si:H film on the convex TIR surface during atomic $\mathrm{H}$ dosing. 


\section{B. Atomic $\mathrm{H}$-source}

The atomic H-source ${ }^{43,44}$ consist of a tungsten capillary (length: $6 \mathrm{~cm}$, diameter $1 \mathrm{~mm}$ ) that is heated by a tungsten filament in which purified $\mathrm{H}_{2}$ (Praxair, purity $>99.999 \%$, delivered by mass flow controller) is dissociated producing an atomic $\mathrm{H}$ beam. The spatial $\mathrm{H}$ output of the source has been extensively calibrated by mass spectrometry measurements as a function of the polar angle for different capillary temperatures $(1800-2600 \mathrm{~K})$ and $\mathrm{H}_{2}$ flows $\left(1.9 \times 10^{-3}-0.42\right.$ sccm $){ }^{43,44}$ However, an uncertainty in the absolute $\mathrm{H}$ flux up to a factor of two cannot be excluded due to uncertainties in the $\mathrm{H}_{2}$ flow and the exact temperature of the capillary. The $\mathrm{H}$ flux onto the substrate can however be changed accurately by varying the distance between the source and the TIR surface of the folded resonator (between 15.4 and $5.4 \mathrm{~cm}$ ). The H-source acts like a point-source and the $\mathrm{H}$ flux therefore shows a $1 / r^{2}$ dependence on the distance $r$ between the substrate and the heated region of the H-source. ${ }^{43,44}$ This procedure guarantees an accurate relative $\mathrm{H}$ dosing with an absolute accuracy within a factor of two. Initial heating of the tungsten filament resulted in a less ppm change in the optical loss of the resonator even when protected by the shutter. This effect might be induced by heating effects of the TIR surface or by creation of radical species from the background gasses and etching from the reactor walls. A similar but opposite effect is observed when the source was cooled down. Furthermore, in control experiments, it was verified that the heated hydrogen source did not influence the measurements when no hydrogen was supplied to the source.

\section{Folded resonator and optical system}

A high-finesse $(\Phi=63000)$, high-Q $\left(\mathrm{Q} \approx 10^{10}\right)$ ultralow-loss monolithic folded optical resonator is employed in the $\mathrm{H}$ dosing experiments [see Fig. 1(b)]. ${ }^{41}$ The atomically smooth total-internal reflection (TIR) surface of the resonator forms the working surface for the experiments after being covered with an a-Si:H thin film. ${ }^{38,45}$ The resonator was fabricated from a single, right-triangular monolith of ultrapure a- $-\mathrm{SiO}_{2} \quad(<50 \mathrm{ppb}$ bulk $\mathrm{OH}$ by weight; optical loss $<2.3 \times 10^{-6} / \mathrm{cm}$ at $1200 \mathrm{~nm}$ ), having a $2.0 \mathrm{~cm}$ edge dimension and a thickness of $0.5 \mathrm{~cm}$. The two planar, highreflectivity coated $(>99.998 \%)$ surfaces and convex TIR surface $(9.0 \mathrm{~cm}$ radius of curvature) were chemomechanically polished to $0.05 \mathrm{~nm}$ root-mean-square surface roughness. The per-pass loss of the resonator was coating-limited, reaching a minimum of $18 \times 10^{-6}$ at $1205 \mathrm{~nm}\left(8299 \mathrm{~cm}^{-1}\right)$, which yielded a base photon storage time (ring-down time) of $5.3 \mu \mathrm{s}$. The ring-down time is inversely proportional to the absolute loss and requires no calibration. The area probed by the evanescent field at the apex of the TIR surface is $\pi \sqrt{2}(85 \times 99) \mu \mathrm{m}^{2}$ for the fundamental resonator mode at $1200 \mathrm{~nm}$, which is fixed in position by the monolithic design, providing a precisely defined sample region. ${ }^{46}$

The resonator was cleaned with high purity methanol after having been exposed to ambient conditions for a protracted time. Subsequently, the folded resonator was mounted in the center of the substrate holder with the total internal reflection (TIR) surface facing the deposition chamber. After basic alignment using a visible laser beam operating at $532 \mathrm{~nm}$ of the in- and outgoing laser beams, the resonator was slowly heated by radiation to the deposition temperature of $120^{\circ} \mathrm{C}$.

The idler of an optical parametric oscillator (Quanta-Ray, MOPO 710) pumped by a seeded, tripled Nd:YAG operating at $30 \mathrm{~Hz}$ (Quanta-Ray, 230-30) provided laser pulses of $6 \mathrm{~ns}$ duration and a characteristic linewidth of $<10 \mathrm{~cm}^{-1}$. Using optical components as indicated in Fig. 1(a), the laser pulse was weakly focused onto the planar surface of the folded resonator using a lens to excite a distribution of low-order modes in the resonator. Fine alignment of the resonator could be realized using only two alignment mirrors positioned outside the UHV setup. A double Fresnel rhomb (Thorlabs, FR600HM) and a Glan-Laser polarizer (Thorlabs, GL-10) are used to adjust the incident laser power and to control the polarization input. Using equal amounts of $s$ - and $p$-polarized input light, the orthogonally polarized ring-down transients were separated using another Glan-Laser polarizer (Thorlabs, GL-10) and simultaneously detected by two freespace-coupled, high-speed, $125 \mathrm{MHz}$, InGaAs photodiode detectors (New Focus, 1811). The average energy per laser pulse needed to obtain a good signal-to-noise ratio was found to be $\approx 0.5 \mathrm{~mJ} /$ pulse, well below the damage threshold of the resonator mirror coatings $(\approx 3 \mathrm{~mJ} /$ pulse $)$. Each individual ring-down time is extracted from the recorded transient using a weighted least-square fit. The statistical properties of the ring-downs can be stored and averaged to acquire higher sensitivity.

\section{Spectroscopic ellipsometry and infrared spectroscopy}

Additional information on the a-Si:H material properties and the influence of $\mathrm{H}$ dosing were obtained by in situ SE and in situ attenuated total reflection (ATR) infrared spectroscopy experiments. ${ }^{47}$ The measurement took place under identical conditions in a separate experiment using GaAs ATR crystals (Harrick) with native oxide. From the SE measurements (photon energy range: $1.5-5.0 \mathrm{eV}$ ), the film thickness and the optical material properties of the a-Si:H thin film were obtained. The ATR infrared spectroscopy measurements (wavenumber range: $800-7000 \mathrm{~cm}^{-1}$, resolution $4 \mathrm{~cm}^{-1}$ ) gave information on the bulk and surface hydride composition for the as-deposited films while also the influence of atomic $\mathrm{H}$ on the (surface) hydride composition was studied.

\section{E. a-Si:H sample preparation}

A $42 \pm 2 \mathrm{~nm} a$-Si:H film was deposited on the TIR surface by thermal decomposition of $\mathrm{SiH}_{4}$ on a hot tungsten filament $\left(\sim 2050^{\circ} \mathrm{C}\right)$ at a pressure of $4 \times 10^{-3}$ mbar (prior to HW ignition). The filament was located $6.8 \mathrm{~cm}$ from the resonator surface which was heated to $120^{\circ} \mathrm{C}$, leading to a growth rate of $\sim 2.5 \mathrm{~nm} / \mathrm{min}$ under conditions where $\mathrm{SiH}_{3}$ is considered to be the dominant growth precursor. ${ }^{48-50}$ Separate depositions studied using infrared spectroscopy 
reveal a dominant contribution of the lower stretching mode and a $70 \%$ smaller contribution of the higher stretching mode with a total hydrogen content of $\sim 13$ at. \%, pointing to a dominance of (di-)vacancies over nanosized voids in the material. This is supported further by spectroscopic ellipsometry measurements, revealing a refractive index of 4.3 (3.6) at a wavelength of $600(1200) \mathrm{nm}$, indicative of dense $a$-Si:H with a minimum contribution of nanosized voids. ${ }^{27,51}$

$\mathrm{H}$ dosing was carried out by cracking a $0.1 \mathrm{sccm} \mathrm{H}_{2}$ flow in the atomic $\mathrm{H}$ source heated to a temperature of $\sim 1850 \mathrm{~K}$ by a filament current of $9 \mathrm{~A}$. The largest $\mathrm{H}$ flux $\left(2 \cdot 10^{14} \mathrm{~cm}^{-2} \mathrm{~s}^{-1}\right)$ was obtained for a distance of $5.4 \mathrm{~cm}$ to the resonator surface while the smallest $\mathrm{H}$ flux $(0.42 \times$ $10^{14} \mathrm{~cm}^{-2} \mathrm{~s}^{-1}$ ) was obtained at the maximum separation between source and resonator of $15.4 \mathrm{~cm}$. Spectroscopic ellipsometry measurements indicate that under these conditions a negligible amount of $a$-Si:H is etched $\left(<10^{-3} \mathrm{~nm} / \mathrm{s}\right.$ at the highest flux). An automated stainless steel shutter protects the substrate during startup of the $\mathrm{H}$ source and provides the opportunity for fast on-and-off switching of the atomic $\mathrm{H}$ flux to the resonator surface.

Both EW-CRDS and ATR infrared spectroscopy measurements reveal that the $a-\mathrm{Si}: \mathrm{H}$ film undergoes structural changes within the first few minutes after deposition and that atomic $\mathrm{H}$ dosing initially removes $\mathrm{Si}-\mathrm{H}_{2}$ and $\mathrm{Si}-\mathrm{H}_{3}$ groups at the surface while inducing minor changes in the bonding configuration subsurface. Because the focus of this work is on studying defect kinetics as a function of atomic $\mathrm{H}$ flux, a fully reversible response to the $\mathrm{H}$ flux is preferred. For this reason, the as-grown film was pretreated with a $2 \times 10^{14} \mathrm{~cm}^{-2} \mathrm{~s}^{-1}$ flux of atomic $\mathrm{H}$ for $2 \mathrm{~h}$ in steps of approximately 30 s (totaling $\sim 1000$ monolayers of $\mathrm{H}$ ), ensuring that the film does not undergo structural changes during the subsequent $\mathrm{H}$ dosing series. During $\mathrm{H}$ pretreatment of the film only minor variations ( $1-3 \mathrm{ppm}$ for $s$-polarization) in the background optical loss of the film were observed.

\section{RESULTS AND DISCUSSION}

\section{A. Controlled H-dosing experiments}

The EW-CRDS signal was measured continuously with the $\mathrm{H}$ flux being varied from $2 \times 10^{14}$ to $0.42 \times 10^{14} \mathrm{~cm}^{-2} \mathrm{~s}^{-1}$ in 11 steps of $30 \mathrm{~s}$, see Fig. 2. The subgap absorption is seen to increase rapidly up to double the original loss level when an $\mathrm{H}$ flux is incident on the film surface, but returns gradually to the original loss level when the flux is turned off.

The initial rate of increase in the loss upon $\mathrm{H}$ dosing (referred to as the creation rate) was determined from exponential fitting of the data and extrapolating to the time the flux was turned on. This shows an almost linear dependence of the initial rate on flux [see Fig. 3(a)]. Moreover, subsequent linear fits of this data show an $s / p$ polarization ratio of $2.8 \pm 0.1$. Because of the $30 \mathrm{~Hz}$ sampling rate of the optical system, this polarization ratio is reached at least $33 \mathrm{~ms}$ after the flux is turned on and may not represent the exact initial $s / p$ ratio upon $\mathrm{H}$ irradiation. The steady-state is attained within $15 \mathrm{~s}$ after the flux is turned on and shows a nonlinear

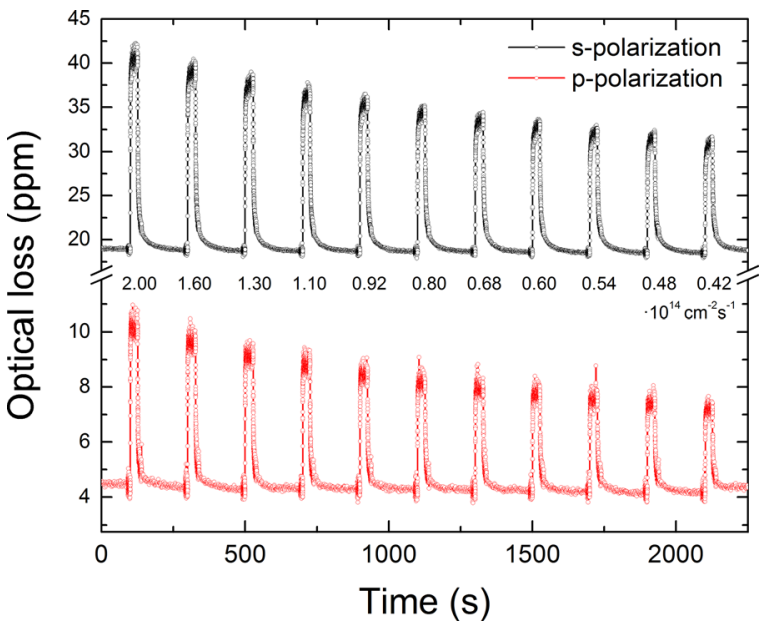

FIG. 2. (Color online) Subgap optical loss as a function of time obtained by EW-CRDS during consecutive $30 \mathrm{~s} \mathrm{H}$ doses with fluxes in the range of $(2-0.42) \times 10^{14} \mathrm{~cm}^{-2} \mathrm{~s}^{-1}$ at a substrate temperature of $120^{\circ} \mathrm{C}$. The optical loss of the resonator without thin film was subtracted for both polarizations. The remaining background loss is consistent with a $2.4 \times 10^{17} \mathrm{~cm}^{-3}$ bulk defect density.

dependence on flux as well as a distinct polarization ratio of $3.7 \pm 0.2$, as can be seen in Fig. 3(b). With increasing flux, the defect absorption also appears to approach a saturation level for both polarization directions. The $p$-polarized optical loss reaches the steady-state faster than the $s$-polarized loss as shown in Fig. 4, though the decay after the flux is turned off occurs at roughly the same rate for both polarization directions. The inset of Fig. 4 shows the inverse of the decay for s-polarization, revealing a distinct hyperbolic dependence for the decay process. This hyperbolic decay over time clearly indicates that a second order process dominates the healing of defects, which is a leading aspect of the kinetic model presented below.

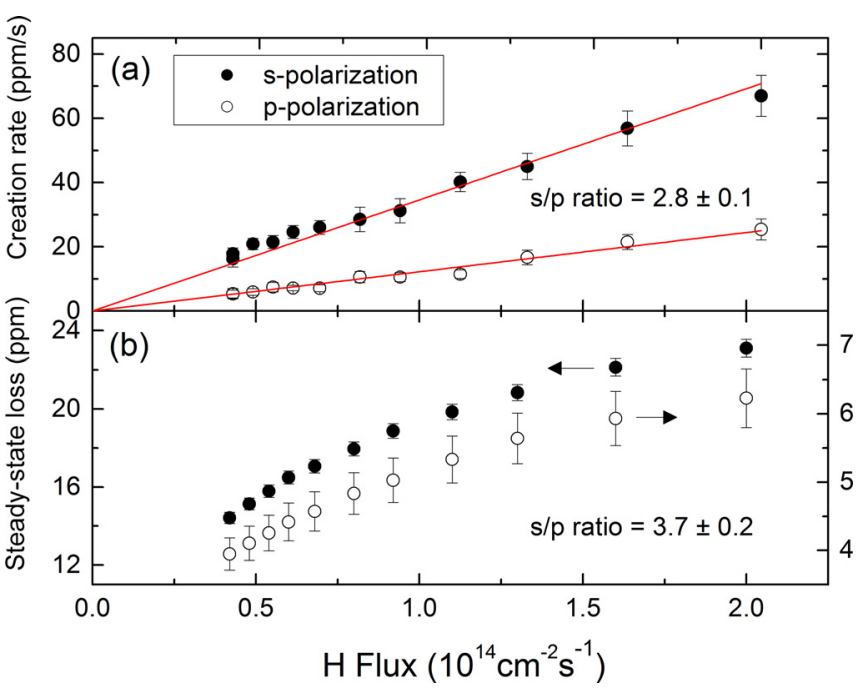

FIG. 3. (Color online) (a) Initial creation rate for both polarizations when the flux is turned on. Each data point is the result of an exponential fit during the first second after the hydrogen dosing is started. Error weighted linear fits reveal an initial $s / p$ ratio of $2.8 \pm 0.1$. (b) Steady-state optical loss as a function of flux. The steady-state $s / p$ ratio as a function of flux is constant within the measurement error with a value of $3.7 \pm 0.2$. 


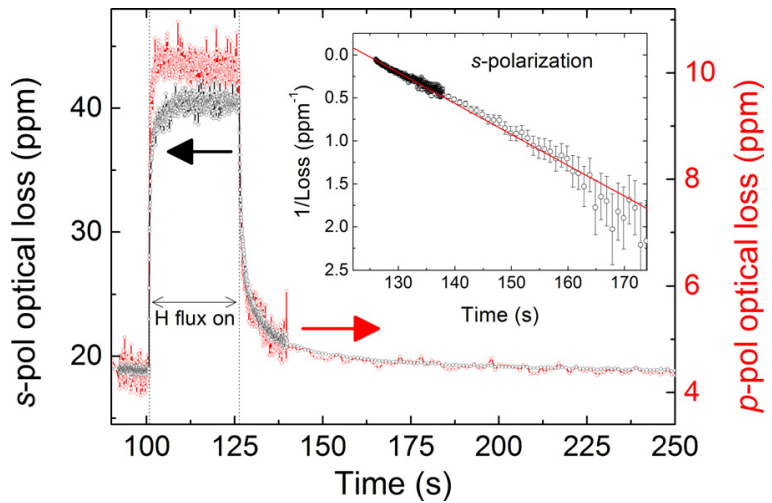

FIG. 4. (Color online) Single dosing cycle at an $\mathrm{H}$ flux of $2.00 \times 10^{14} \mathrm{~cm}^{-2} \mathrm{~s}^{-1}$, clearly showing the polarization anisotropy as a function of time. The inset depicts the inverse of the $s$-polarized decay after the $\mathrm{H}$ flux is terminated along with a linear fit, revealing its hyperbolic character.

\section{B. Model}

A first experimental observation is that repeated $\mathrm{H}$ dosing does not affect the background optical loss of the film. This confirms that no structural changes of the film are taking place (such as etching or significant additional hydrogen incorporation), and that the pre-existing defect density, both on the surface and in the bulk, remains unaffected by repeated small $\mathrm{H}$ doses.

The optical loss $\Gamma(t)$ can be directly related to the defect density in the thin film by the expression

$$
\Gamma(t)=\int_{0}^{h} \sigma_{\text {defect }} N_{\text {defect }}(z, t) I(z) d z,
$$

where $I(z)$ is the electric field intensity in the film during ring-down, $N_{\text {defect }}(z, t)$ the distribution of defects in the film, $\sigma_{\text {defect }}$ the optical absorption cross-section at the wavelength under consideration, and $h$ the thickness of the film. The electric field intensity as a function of depth can be calculated using Fresnel reflection-transmission coefficients, ${ }^{52}$ while we assume the absorption cross-section is independent of depth with a value of $\sim 10^{-16} \mathrm{~cm}^{2}$. 53

The $E$-field intensity depends critically on the polarization direction; see Fig. 5 for the calculated E-fields in a $42 \mathrm{~nm}$ film. Assuming an isotropic orientation of defects, the $s / p$ polarization ratio can be employed to determine the depth up to which defects are induced by the atomic $\mathrm{H}$ flux. An $s / p$ ratio of $2.8 \pm 0.1$ was determined for the initial creation rate after the flux is turned on [Fig. 3(a)], which for a $42 \mathrm{~nm}$ thick film corresponds with the ratio of E-field intensities just below the surface of the a-Si:H film. Furthermore, the increased $s / p$ ratio of $3.7 \pm 0.2$ observed in the steady-state can be accounted for by an exponentially decaying defect distribution with a characteristic $1 / 10$ penetration depth of $\sim 15 \mathrm{~nm}$. Considering that the penetration depth is significantly lower than the film thickness, it is tentatively assumed that thicker films would show a similar response to $\mathrm{H}$ dosing. The $s / p$ ratio and this penetration depth are roughly the same for all fluxes, while the absolute absorption is nonlinear in flux [Fig. 3(b)]. The nonlinearity is therefore not a result of a

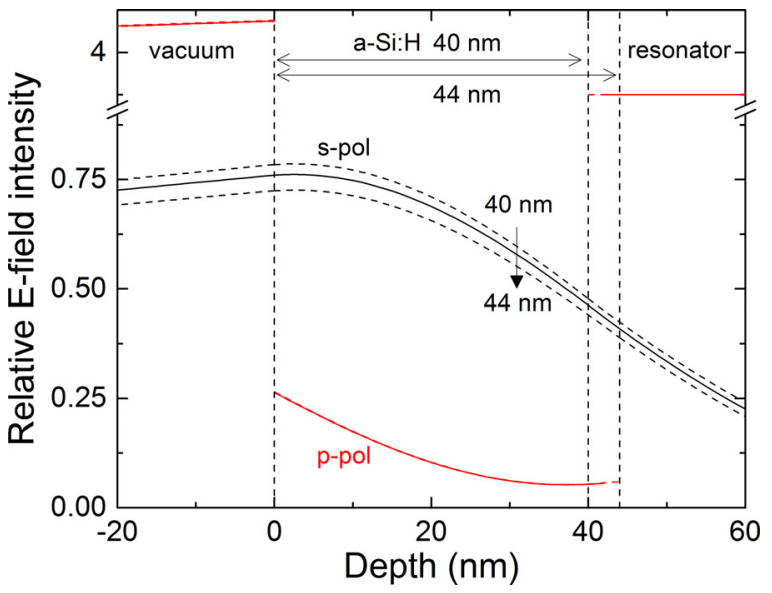

FIG. 5. (Color online) Calculated $s$ - and $p$-polarization relative E-fields at $1200 \mathrm{~nm}$ using refractive indices of $1.49,3.60$ and 1.00 for the resonator, $42 \pm 2 \mathrm{~nm}$ a-Si:H thin film and vacuum, respectively. The plane-wave has an angle of incidence of $45^{\circ}$ at the resonator-thin film interface and is at an angle of $16.5^{\circ}$ within the a-Si:H film. An evanescent field is formed in the vacuum. The $p$-polarization E-field has a negligible sensitivity to the film thickness.

variable penetration depth, but can be explained by the $\mathrm{H}$ kinetics in a thin $a$-Si:H film. It is of importance to note that the $s / p$ ratios observed in the data do not correspond to fields on the vacuum side of the film surface, where an $s / p$ ratio of 0.13 is expected. This implies that surface defects have (1) a low absorption cross-section at $1200 \mathrm{~nm}$, or (2) are only subject to the $E$-field intensity just within the film, or (3) are subject to a fast $\mathrm{H}$-induced passivation mechanism (e.g., a Kisliuk type of adsorption-abstraction equilibrium ${ }^{54}$ ). The background loss observed in between $\mathrm{H}$ dosing cycles, meanwhile, is consistent with a bulk defect density of $2.4 \times$ $10^{17} \mathrm{~cm}^{-3}$.

Using a kinetic model, we will show that our data can be fully accounted for by assuming that all $\mathrm{H}$-induced defect creation observed in our data occurs at the subsurface. The increase in subsurface defect absorption during $\mathrm{H}$ dosing implies that atomic $\mathrm{H}$ residing in the $a$-Si:H network can give rise to additional defect states in the gap. This suggests that mobile atomic $\mathrm{H}$ penetrating into the bulk of the film encounters locations in the network where it is immobilized and causes the formation of a defect. A likely candidate for this process is the (reversible) insertion of atomic $\mathrm{H}$ in strained $\mathrm{Si}-\mathrm{Si}$ bonds, ${ }^{55-59}$ leading to a short-lived configuration of a single bonded $\mathrm{H}$ atom $(\mathrm{Si}-\mathrm{H})$ with a corresponding dangling bond defect $(\mathrm{Si} \bullet$,

$$
\mathrm{Si}-\mathrm{Si}+\mathrm{H} \leftrightarrow \mathrm{Si} \bullet--\mathrm{H}-\mathrm{Si} .
$$

Note that Reaction (2) occurs in both directions, with both insertion of $\mathrm{H}$ and desorption of $\mathrm{H}$, which is an essential part of the kinetic model. A short-lived defect naturally explains the complete reversibility observed in the data. The dangling bonds accompanied by neighboring $\mathrm{Si}-\mathrm{H}$ bonds are designated as defect complexes to differentiate them from preexisting dangling bonds. Because of the limited penetration depth observed for defect creation and the apparent 
saturation of defects with increasing flux, combined with the $t^{-1}$ dependence of the optical loss decay after the flux is terminated (see the inset of Fig. 4), the induced defect density must undergo a quadratic loss process. We propose the recombination of a defect complex with a mobile $\mathrm{H}$ atom

$$
\mathrm{Si} \bullet--\mathrm{H}-\mathrm{Si}+\mathrm{H} \rightarrow \mathrm{Si}-\mathrm{Si}+\mathrm{H}_{2} .
$$

The molecular hydrogen formed in this process is considered inert in terms of defect creation and is expected to diffuse out of the film. It is, however, equally possible that molecular hydrogen remains trapped in voids and divacancies within the $a$-Si:H film. ${ }^{45,60,61}$

The abstraction of pre-existing bonded $\mathrm{H}$ in the bulk $a-\mathrm{Si}: \mathrm{H}$ and the subsequent passivation of the resulting dangling bonds are not included in the kinetic model, as was done by Das et al. in the analysis of their ESR data. ${ }^{35}$ Although an abstraction-passivation mechanism will also lead to a limited penetration depth for defect creation, the main objection against this reaction scheme is that defects created through abstraction are not self-healing and therefore cannot account for the complete reversibility observed in the data. As we will show, Reactions (2) and (3) are sufficient reaction pathways to account for our data.

The kinetic equation for $\mathrm{H}$-induced defect complexes can be written as

$$
\begin{aligned}
\frac{\partial N_{c}(z, t)}{\partial t}= & k_{\text {ins }} N_{S} N_{H}(z, t)-k_{r e c} N_{c}(z, t) N_{H}(z, t) \\
& -\frac{N_{c}(z, t)}{\tau},
\end{aligned}
$$

where $N_{c}(z, t)$ is the density of inserted $\mathrm{H}$ complexes, $N_{H}(z, t)$ the density of mobile atomic $\mathrm{H}, k_{\text {ins }}$ is the rate constant for creation of defect complexes, $N_{S}$ the density of strained $\mathrm{Si}-\mathrm{Si}$ bonds, $\tau$ the self-healing life time of the complex, and $k_{\text {rec }}$ the recombination rate constant for the process in Eq. (3). We assume that the density of available insertion sites $N_{S}$ is sufficiently high to be considered a local constant. Atomic $\mathrm{H}$ diffuses through the film, leading to a corresponding kinetic equation for $N_{H}$,

$$
\begin{aligned}
\frac{\partial N_{H}(z, t)}{\partial t}= & D_{H} \frac{\partial^{2} N_{H}(z, t)}{\partial z^{2}}-k_{\text {ins }} N_{S} N_{H}(z, t) \\
& -k_{\text {rec }} N_{c}(z, t) N_{H}(z, t)+\frac{N_{c}(z, t)}{\tau},
\end{aligned}
$$

with $D_{H}$ the diffusion coefficient for mobile atomic $\mathrm{H}$ in the film. We assume that $D_{H}$ is constant over the flux range considered.

The following boundary condition for the mobile $\mathrm{H}$ density $N_{H}$ at the surface of the film is implemented:

$$
-\left.D_{H} \frac{\partial N_{H}(z, t)}{\partial z}\right|_{z \downarrow 0}=f \Phi_{H} .
$$

The boundary condition at the a-Si:H-resonator interface is a simple Neumann boundary condition, as atomic $\mathrm{H}$ is not expected to penetrate into the fused silica folded cavity

$$
-\left.D_{H} \frac{\partial N_{H}(z, t)}{\partial z}\right|_{z \uparrow h}=0 .
$$

The parameter $\Phi_{H}$ is the hydrogen flux incident at the surface and $f$ the effective fraction of this flux entering the film. Note that this boundary condition bypasses any interactions of $\mathrm{H}$ with the surface of the film by only considering the effective fraction of the flux contributing to subsurface defect creation. The concentration of mobile $\mathrm{H}$ just below the surface $\left(\left.N_{H}\right|_{z \downarrow 0}\right)$ approaches steady-state within $\left(k_{\text {ins }} N_{S}\right)^{-1} \approx 10^{-3}$ s (see below) after the $\mathrm{H}$ flux is turned on, which is much faster than the experimental time resolution of $33 \mathrm{~ms}$. The experiment is therefore not sensitive to the initial kinetics of atomic $\mathrm{H}$ impinging on the surface and the atomic $\mathrm{H}$ present just below the surface of the film. In other words, the fraction $f$ is an effective value related to the consumption of $\mathrm{H}$ in recombination processes in the subsurface region. The following relation, derived from Eqs. (4)-(7), holds for all fluxes $\Phi_{H}$ :

$$
\frac{1}{2} f \Phi_{H}=\left.\int_{0}^{d} k_{r e c} N_{c}(z, t) N_{H}(z, t) d z\right|_{t \rightarrow \infty} .
$$

The fraction $f$ is therefore a measure of the thickness integrated subsurface recombination rate.

By fitting the model described by Eqs. (4)-(7) to the EW-CRDS data via Eq. (1), the parameters $k_{\text {ins }} N_{S}, k_{\text {rec }}, \tau$, $D_{H}$, and $f$ are determined. In the fitting procedure, the total mean squared error (MSE) over time is simultaneously minimized for the $\mathrm{H}$ induced loss of the two highest and the two lowest fluxes, leading to convergence of all five parameters. The lowest total MSE was obtained for a film thickness of $41 \mathrm{~nm}$, though varying the film thickness by a few nanometers has only a small effect on the $E$-field intensities and, hence, on the quality of the fit.

We can account for all the features in the data, including the polarization anisotropy, steady-state loss, and the initial creation/healing rate as a function of $\mathrm{H}$ flux using $f=(5.5 \pm 0.1) \times 10^{-3}, \quad \tau=0.25 \pm 0.01 \mathrm{~s}, \quad k_{\text {ins }} N_{S}=800_{-500}^{+100}$ $\mathrm{s}^{-1}, k_{\text {rec }}=10_{-6}^{+1} \times 10^{-16} \mathrm{~cm}^{3} \mathrm{~s}^{-1}$ and $D_{H}=3.6_{-2.3}^{+0.5} \times 10^{-11}$ $\mathrm{cm}^{2} \mathrm{~s}^{-1}$ (see Fig. 6). All values are determined within a $95 \%$ confidence interval, with the errors in $k_{\text {ins }} N_{S}, k_{r e c}$, and $D_{H}$ being interdependent. The model predicts a near-surface steady-state density of induced defects $N_{c}=4 \times 10^{17} \mathrm{~cm}^{-3}$ and a density of mobile atomic $\mathrm{H}$ as low as $N_{H}=6 \times 10^{15} \mathrm{~cm}^{-3}$ at an $\mathrm{H}$ flux of $2 \times 10^{14} \mathrm{~cm}^{2} \mathrm{~s}^{-1}$; see Fig. 7 for the calculated $\mathrm{H}$ induced defect and mobile $\mathrm{H}$ density profiles as a function of depth. The model predicts a saturation defect density $k_{\text {ins }} N_{S} / k_{\text {rec }}=8 \times 10^{17} \mathrm{~cm}^{-3}$ at high $\mathrm{H}$ flux conditions $\left(\Phi_{H}>10^{16} \mathrm{~cm}^{-2} \mathrm{~s}^{-1}\right)$, consistent with the ESR results of Das et al. $\left(10^{13} \mathrm{~cm}^{-2}\right.$ with a penetration depth of $\left.100 \mathrm{~nm}\right){ }^{35}$

The fact that the $p$-polarized optical loss reaches the steady-state faster than the $s$-polarized loss can be attributed to the difference in $E$-field intensities as a function of depth; the $s$-polarized loss is more sensitive to the small increases in defect density deeper into the film that occur several seconds after the $\mathrm{H}$ flux has been turned on. 

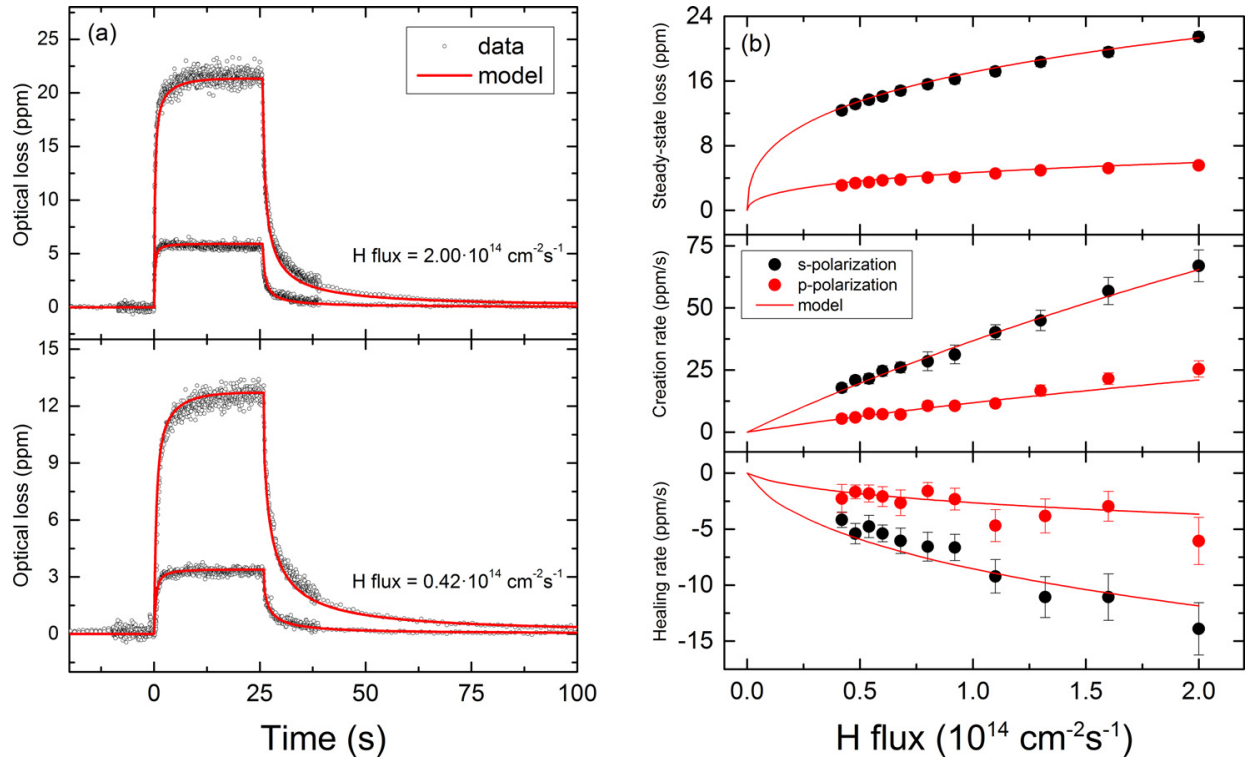

FIG. 6. (Color online) Model fits to the data with $k_{\text {ins }} N_{S}=800 \mathrm{~s}^{-1}, k_{\text {rec }}=10^{-15} \mathrm{~cm}^{3} \mathrm{~s}^{-1}, \tau=0.25 \mathrm{~s}, D_{H}=3.6 \times 10^{-11} \mathrm{~cm}^{2} \mathrm{~s}^{-1}$ and $f=5.5 \times 10^{-3}$, (a) the highest and lowest flux data and model as a function of time with background loss subtracted for both polarization directions, (b) steady-state induced loss, initial creation/healing rate when the flux is turned on/off as a function of $\mathrm{H}$ flux compared to the model prediction.

\section{Model discussion}

\section{Surface processes}

The EW-CRDS data can be completely accounted for by interactions of $\mathrm{H}$ in the subsurface of the a-Si:H film, using three reaction pathways (insertion, desorption, and recombination) without there being a clear contribution of additional defects created at the surface during $\mathrm{H}$ dosing. As described earlier, this could be due to rapid equilibration of the surface defect density with the impinging $H$ flux, well within the $30 \mathrm{~ms}$ time resolution of the experiment. In this case, the lack of need to include terms for surface defect creation in the model is self-evident. It can also be argued that no measurable change in the surface defect density from atomic $\mathrm{H}$ dosing would be detectable at all at treatment temperatures

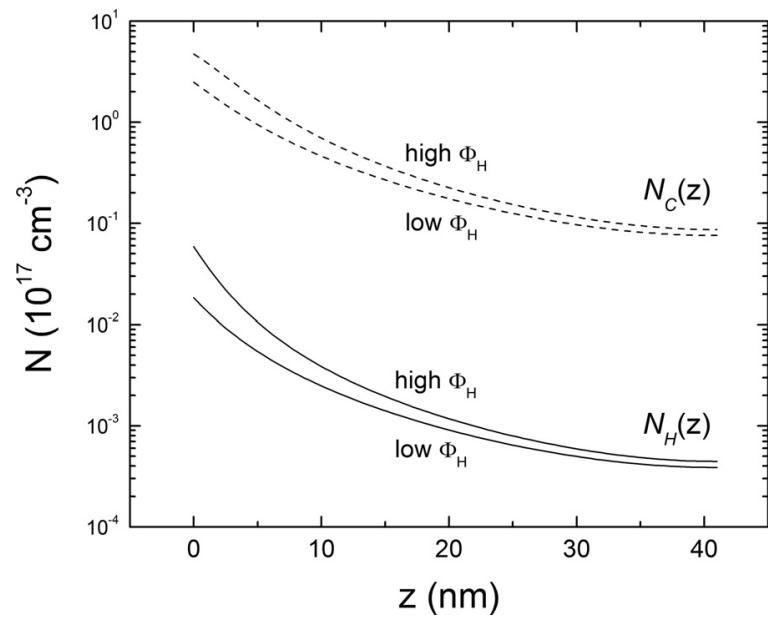

Fig. 7. Calculated defect complex $\left(N_{C}\right)$ and mobile $\mathrm{H}\left(N_{H}\right)$ profiles as a function of depth for the highest and lowest $\mathrm{H}$ fluxes $\left(2.00 \times 10^{14}\right.$ and 0.42 $\times 10^{14} \mathrm{~cm}^{-2} \mathrm{~s}^{-1}$, respectively). The $1 / 10$ penetration depth for the defect complex is $\sim 15 \mathrm{~nm}$, opposed to $\sim 8 \mathrm{~nm}$ for the mobile $\mathrm{H}$ density. of $120^{\circ} \mathrm{C}$, even with higher time resolution. First of all, abstraction and passivation of $\mathrm{H}$ radicals on the film surface are first-order with respect to the incident flux at these temperatures, ${ }^{17,20}$ leading to an $\mathrm{H}$ coverage (and corresponding defect coverage) which is independent of flux. In this case, a fast passivation mechanism will maintain the surface $\mathrm{H}$ coverage at the (over-)saturated level prior to dosing. ${ }^{17,20}$ This mechanism is driven either by a large reservoir of physisorbed atomic $\mathrm{H}$ at the surface, such as in the hot atom Kisliuk model employed by Widdra et al. ${ }^{19}$ or by a subsurface atomic $\mathrm{H}$ reservoir. ${ }^{62}$ Also, at temperatures below $30{ }^{\circ} \mathrm{C}$, the surface is stable, ${ }^{22,63-65}$ so that no desorption of chemisorbed $\mathrm{H}$ will occur after dosing is stopped. It is therefore plausible that the surface defect coverage is not significantly altered when the $\mathrm{H}$ flux is turned on, especially considering the large $\mathrm{H}$ pretreatment applied to the film, which will have removed any surface configurations unstable to impinging atomic $\mathrm{H}$. In any event, EW-CRDS measurements over a wider range of subgap photon energies are desirable before drawing any definitive conclusions concerning surface defect kinetics in relation to $\mathrm{H}$ dosing.

The effective $\mathrm{H}$ flux entering the subsurface of the film is only a small fraction $f=5.5 \times 10^{-3}$ of the total atomic $\mathrm{H}$ flux incident at the surface. However, the fraction $f$ should not be considered the probability of atomic $\mathrm{H}$ to enter the film bulk from the surface, as it also includes the amount of desorption of subsurface $\mathrm{H}$ back to the surface or back into the gas-phase. Our model predicts a reservoir of mobile atomic $\mathrm{H}$ just below the surface of the film $\left(\sim 10^{8} \mathrm{~cm}^{-2}\right.$ in the first monolayer), which may contribute to surface abstraction and passivation processes. The rate at which atomic $\mathrm{H}$ is returned to the surface cannot be determined, however, so that no conclusions can be drawn about the significance of this reservoir for surface processes. 


\section{Defect complex and diffusion}

The defect complex observed in our data can be identified as a shallow trapping site for atomic $\mathrm{H}$ considering the relatively short lifetime $\tau$ of $0.25 \mathrm{~s}$ compared to the much longer lifetime of deeply trapped $\mathrm{H}$ of around $600 \pm 200$ days (at $180^{\circ} \mathrm{C}$ ), as determined by Branz et al ${ }^{66}$ A preliminary analysis of an $\mathrm{H}$ dosing temperature series revealed an activation energy of $\sim 0.25 \mathrm{eV}$ for $\mathrm{H}$ desorption from the defect complex, assuming Arrhenius-type behavior. This activation energy for desorption from the defect complex is comparable to the barrier between shallow trap states and transport states of $0.2-0.5 \mathrm{eV}$ determined for $\mathrm{c}-\mathrm{Si}^{67,68}{ }^{67-S i},{ }^{32}$ or $\mathrm{pm} / \mu \mathrm{c}-$ $\mathrm{Si}^{69,70} \mathrm{In}$ addition, it is well known that diffusion of hydrogen into a-Si:H from a plasma or other external sources is dictated by these shallow trap states. ${ }^{28-33}$ We do not expect the defect complex (i.e., strained $\mathrm{Si}-\mathrm{Si}$ bonds) to be the dominant shallow trapping site in a-Si:H, however, since interstitial sites and unstrained $\mathrm{Si}-\mathrm{Si}$ bonds are far more abundant (both $>10^{22} \mathrm{~cm}^{-3}$ ) and are likely to provide ample shallow trapping states for hydrogen, as indicated by the activated diffusion in single-crystal silicon. ${ }^{67,68}$ Our model, given by Eqs. (4)-(7), implicitly assumes that shallow trapping events not leading to defect absorption occur on time-scales much faster than the formation of defect complexes, so that the diffusion coefficient $D_{H}$ can be considered constant as a function of time. This is justified by the large number of potential nondefect related trapping sites, which will lead to a fast equilibrium between mobile $\mathrm{H}$ and the dominant shallow traps when the flux is turned on. Further supporting this is the high diffusion coefficient of mobile $\mathrm{H}$ $\left(D_{H}=3.6_{-2.3}^{+0.5} \times 10^{-11} \mathrm{~cm}^{2} \mathrm{~s}^{-1}\right)$ derived from our data: a penetration depth for mobile atomic $\mathrm{H}$ of $\sim 3 \mathrm{~nm}$ (Fig. 7) is achieved within $3 \mathrm{~ms}$ after the flux is turned on, while the time-scale for defect complexes to equilibrate with the mobile $\mathrm{H}$ density is several seconds. Note that the diffusion coefficient $D_{H}$ strongly affects the H-induced defect profile $N_{C}$ as a function of depth and time so that it can be obtained from the data with reasonable accuracy, despite the time resolution of only $33 \mathrm{~ms}$.

An important advantage of determining the diffusion coefficient of atomic $\mathrm{H}$ from EW-CRDS data over SIMS analysis of atomic deuterium treated a-Si:H films is that the latter is only sensitive to deep trapping events (i.e., the exchange of bonded $\mathrm{Si}-\mathrm{H}$ with $\mathrm{Si}-\mathrm{D}$ ). As pointed out by Kemp and Branz et al., capture of D by direct exchange with bonded $\mathrm{H}$ is the dominant trapping mechanism in a-Si:H. ${ }^{71}$ A front of atomic D moving into the a-Si:H film can therefore be turned into atomic $\mathrm{H}$ after the first few monolayers by the efficient exchange at the numerous $\mathrm{Si}-\mathrm{H}$ sites, which will limit the observed diffusion coefficient of D from the gas-phase. Our experiment is not directly sensitive to these exchange events, only to the trapping of $\mathrm{H}$ at a minority of relatively shallow trapping sites and therefore provides a more accurate lower limit on the $\mathrm{H}$ diffusion coefficient. The diffusion coefficient of $3.6_{-2.3}^{+0.5} \times 10^{-11} \mathrm{~cm}^{2} \mathrm{~s}^{-1}$ is similar to that inferred by Das et al. from ESR data $\left(\sim 10^{-10} \mathrm{~cm}^{2} \mathrm{~s}^{-1}\right)^{35}$ and approaches the value obtained for $\mathrm{c}-\mathrm{Si}$ by Van
Wieringen and Warmoltz, as well as Seager and Anderson $\left(\sim 10^{-8} \mathrm{~cm}^{2} \mathrm{~s}^{-1}\right.$, extrapolated to $\left.120^{\circ} \mathrm{C}\right){ }^{67,72}$ The value we obtain for mobile $\mathrm{H}$ diffusion in a-Si:H is sufficiently high to fulfill an important parameter in Branz's $\mathrm{H}$ collision model. $^{73,74}$

The inserted $\mathrm{H}$ density during the steady-state (Fig. 7) decays to $1 / 10$ of its value at the surface within $\sim 15 \mathrm{~nm}$. The penetration depth for $\mathrm{H}$ induced defect creation in a-Si:H determined by Das et al. using ESR was on the order of $100 \mathrm{~nm} .{ }^{35} \mathrm{SE}$ studies by Kail et al. and Fontcuberta i Morral et al. showed that a $25 \mathrm{~nm}$ hydrogen-rich subsurface layer is formed during hydrogen plasma-etching of an a-Si:H film, ${ }^{6,69,75}$ further indicating that a wide range of penetration depths for $\mathrm{H}$ from an external source is observed. This difference in penetration depth may also be attributable to the use of plasma in these cases, where energetic $\mathrm{H}$ ion bombardment could be argued to lead to greater penetration depths than would be achievable with the neutral (low-energy) hydrogen flux used in this work. Similar to Das et al., ${ }^{35}$ the penetration depth $\delta_{C}$ for defect formation can be described by

$$
\delta_{C} \approx \sqrt{\frac{D_{H}}{k_{\text {ins }} N_{S}}} .
$$

Both diffusion coefficient $D_{H}$ and strained bond density $N_{S}$ can be expected to easily vary an order of magnitude depending on a-Si:H microstructure; a wide range of penetration depths is therefore likely. Equation (9) only holds for high $\mathrm{H}$ fluxes $\left(\Phi_{H}>10^{16} \mathrm{~cm}^{-2} \mathrm{~s}^{-1}\right)$, in the limit of $k_{\text {rec }} N_{H} \gg$ $1 / \tau$, where the recombination process dominates the desorption process. At the low fluxes employed in our experiments, the limit $k_{\text {rec }} N_{H} \ll 1 / \tau$ applies, and the penetration depth (defined as 10\% of induced defect density at the surface) is approximately given by

$$
\delta_{C} \approx 4\left(\frac{D_{H}^{2}}{\tau f \Phi_{H} k_{\text {ins }} N_{S} k_{\text {rec }}}\right)^{1 / 3} .
$$

The decay of induced defects with depth is not exponential in this case, but follows a $z^{-2}$ dependence. The flux dependence gives a variation of penetration depth between 7 and $11 \mathrm{~nm}$ for $\Phi_{H}=0.42 \times 10^{14}$ and $2 \times 10^{14} \mathrm{~cm}^{-2} \mathrm{~s}^{-1}$, respectively, but this does not significantly affect the observed steady-state $s / p$ ratio as most of the defect absorption occurs in the first $5 \mathrm{~nm}$ from the surface, irrespective of flux.

In as-grown material, the mobile $\mathrm{H}$ density was estimated by Branz to be on the order of $10^{10} \mathrm{~cm}^{-3}\left(210^{\circ} \mathrm{C}\right)$ or $10^{1} \mathrm{~cm}^{-3}\left(25^{\circ} \mathrm{C}\right),{ }^{76}$ which is well below the limit of $k_{\text {rec }} N_{H}$ $\ll 1 / \tau$ for the desorption process to dominate the recombination process. Taking this loss process into account is therefore only relevant in the quantitative interpretation of experimental results involving the introduction of large quantities of atomic $\mathrm{H}$ to a-Si:H films, such as during growth, deuteration, and $\mathrm{H}$ annealing of a-Si:H films. Sriraman and Valipa et al. determined through molecular 
dynamics simulations that repeated insertion of $\mathrm{H}$ in strained $\mathrm{Si}-\mathrm{Si}$ bonds leads to network relaxation and atomic rearrangement processes. ${ }^{77-79}$ Recombination events accompanying the insertion reactions may also be relevant to crystallization, as each recombination event releases up to $4.5 \mathrm{eV}$ of energy in the vicinity of the strained $\mathrm{Si}-\mathrm{Si}$ bond. We do not observe significant structural changes in the film during repeated $\mathrm{H}$ dosing cycles, however, which is attributed to the low atomic $\mathrm{H}$ fluxes and short dosing times during the EW-CRDS experiments, as well as the significant pretreatment of the film with atomic hydrogen.

\section{SUMMARY AND CONCLUSIONS}

By measuring the subgap absorption of HW-CVD grown a-Si:H during low flux $\mathrm{H}$ exposure by time resolved, in situ EW-CRDS, the kinetics of subsurface atomic $\mathrm{H}$ was studied at a substrate temperature of $120^{\circ} \mathrm{C}$. The main conclusions of this work are summarized as follows:

(1) Fully reversible defect creation under $\mathrm{H}$ exposure is observed, with no noticeable passivation of pre-existing defects occurring during repeated $\mathrm{H}$ dosing. Using the polarization anisotropy of the absorption, a limited penetration depth of no more than $\sim 15 \mathrm{~nm}$ is determined. A kinetic model is presented employing a self-healing "defect complex," likely a Si-H/dangling bond configuration resulting from the insertion of $\mathrm{H}$ in a strained $\mathrm{Si}-\mathrm{Si}$ bond, which accurately describes the EW-CRDS data as a function of $\mathrm{H}$ flux. The lifetime of the defect complex determined from the model is $0.25 \pm 0.01 \mathrm{~s}$.

(2) No effect of $\mathrm{H}$ dosing was detected on the surface defect density of a-Si:H. This is likely due to first-order reactions being dominant at $120^{\circ} \mathrm{C}$, which combined with a fast passivation mechanism, leads to negligible perturbation of the surface $\mathrm{H}$ coverage upon $\mathrm{H}$ irradiation. However, the possibility of a low absorption cross section for surface defects at the measured wavelength cannot be excluded.

(3) Based on the $t^{-1}$ dependence of the absorption decay after the $\mathrm{H}$ flux is turned off, as well as the finite depth for defect creation and saturation of the defect density at increased $\mathrm{H}$ fluxes, a second order process takes place whereby the defect complex acts as a recombination center for the production of $\mathrm{H}_{2}$, consequently reducing the density of mobile $\mathrm{H}$ significantly within $20 \mathrm{~nm}$ below the surface. The recombination rate constant $k_{\text {rec }}=10_{-6}^{+1} \times 10^{-16} \mathrm{~cm}^{3} \mathrm{~s}^{-1}$ is very low, however, so that recombination will only play a significant part in atomic $\mathrm{H}$ kinetics at increased mobile $\mathrm{H}$ densities occurring during growth, deuteration, and $\mathrm{H}$ annealing. It should be emphasized, however, that the defects considered here involve a neutral atomic $\mathrm{H}$ flux, while the effect of $\mathrm{H}$ ions present during plasma processing remains unknown.

(4) A high diffusion coefficient of $3.6_{-2.3}^{+0.5} \times 10^{-11} \mathrm{~cm}^{2} \mathrm{~s}^{-1}$ for mobile atomic $\mathrm{H}$ is derived from the model, similar to that found by Das et al. ${ }^{35}$ and close to the value obtained for c-Si by Van Wieringen and Warmoltz, as well as Seager and Anderson. ${ }^{67,72}$ This demonstrates that atomic $\mathrm{H}$ can penetrate quickly into a-Si:H from an external source, in the absence of deep trapping sites, although the penetration depth is limited to a few tens of nanometers due to recombination. This can be observed in the EW-CRDS experiment, where a $1 / 10$ penetration depth for defects of $15 \mathrm{~nm}$ is achieved after $15 \mathrm{~s}$, leading to an effective diffusion coefficient on the order of $10^{-13}$ $\mathrm{cm}^{2} \mathrm{~s}^{-1}$. By separating the contributions of mobile $\mathrm{H}$ and trapped $\mathrm{H}$ in our model, the underlying kinetics of atomic $\mathrm{H}$ transport could be obtained for the case of neutral $\mathrm{H}$ on a pretreated a-Si:H film.

\section{ACKNOWLEDGMENT}

The authors would like to thank W. Beyer of Forschungszentrum Jülich for sharing his insights on hydrogen transport in a-Si:H with us.

${ }^{1}$ R. A. Street, Hydrogenated Amorphous Silicon (Cambridge University, Cambridge, 1991).

${ }^{2}$ D. L. Staebler and C. R. Wronski, Appl. Phys. Lett. 31, 292 (1977).

${ }^{3}$ G. Dingemans, M. N. van den Donker, D. Hrunski, A. Gordijn, W. M. M. Kessels, and M. C. M. van de Sanden, Appl. Phys. Lett. 93, 111914 (2008).

${ }^{4}$ I. Kaiser, N. H. Nickel, W. Fuhs, and W. Pilz, Phys. Rev. B 58, R1718 (1998).

${ }^{5}$ N. Layadi, P. R. I. Cabarrocas, B. Drevillon, and I. Solomon, Phys. Rev. B 52, 5136 (1995).

${ }^{6}$ A. F. i Morral and P. R. i Cabarrocas, Eur. Phys. J.: Appl. Phys. 35, 165 (2006).

${ }^{7}$ K. Saitoh, M. Kondo, M. Fukawa, T. Nishimiya, A. Matsuda, W. Futako, and I. Shimizu, Appl. Phys. Lett. 71, 3403 (1997).

${ }^{8}$ H. M. Branz, Solid State Commun. 105, 387 (1998).

${ }^{9}$ K. Morigaki and H. Hikita, Phys. Rev. B 76, 085201 (2007).

${ }^{10}$ S. Zafar and E. A. Schiff, Phys. Rev. B 40, 5235 (1989).

${ }^{11}$ A. H. M. Smets, C. Wronski, M. Zeman, and M. C. M. van de Sanden, Mater. Res. Soc. Proc. 1245, A14.02 (2010).

${ }^{12}$ J. Melskens et al., Sol. Energy Mater. Sol. Cells 129, 70 (2014).

${ }^{13}$ C. R. Wronski and X. Niu, IEEE J. Photovoltaics 4, 778 (2014).

${ }^{14} \mathrm{~J}$. Melskens et al., IEEE J. Photovoltaics 4, 1331 (2014).

${ }^{15}$ J. J. Boland, Adv. Phys. 42, 129 (1993).

${ }^{16}$ A. Dinger, C. Lutterloh, and J. Küppers, Chem. Phys. Lett. 311, 202 (1999).

${ }^{17}$ M. C. Flowers, N. B. H. Jonathan, A. Morris, and S. Wright, Surf. Sci. 396, 227 (1998).

${ }^{18}$ P. Gupta, V. L. Colvin, and S. M. George, Phys. Rev. B 37, 8234 (1988).

${ }^{19}$ W. Widdra, S. I. Yi, R. Maboudian, G. A. D. Briggs, and W. H. Weinberg, Phys. Rev. Lett. 74, 2074 (1995).

${ }^{20}$ S. Inanaga, F. Rahman, F. Khanom, and A. Namiki, J. Vac. Sci. Technol., A 23, 1471 (2005).

${ }^{21}$ Y. Wu et al., Phys. Rev. Lett. 77, 2049 (1996).

${ }^{22}$ W. Beyer, Physica B 170, 105 (1991).

${ }^{23}$ I. An, Y. M. Li, C. R. Wronski, and R. W. Collins, Phys. Rev. B 48, 4464 (1993).

${ }^{24}$ R. W. Collins, J. Koh, A. S. Ferlauto, P. I. Rovira, Y. Lee, R. J. Koval, and C. R. Wronski, Thin Solid Films 364, 129 (2000).

${ }^{25}$ H. Fujiwara, M. Kondo, and A. Matsuda, Phys. Rev. B 63, 115306 (2001).

${ }^{26}$ A. A. Langford, M. L. Fleet, B. P. Nelson, W. A. Lanford, and N. Maley, Phys. Rev. B 45, 13367 (1992).

${ }^{27}$ A. H. M. Smets, W. M. M. Kessels, and M. C. M. van de Sanden, Appl. Phys. Lett. 82, 1547 (2003).

${ }^{28}$ B. Abeles, L. Yang, D. Leta, and C. Majkrzak, J. Non-Cryst. Solids 97-98, 353 (1987).

${ }^{29}$ W. Beyer, Phys. Status Solidi A 159, 53 (1997).

${ }^{30}$ W. B. Jackson and C. C. Tsai, Phys. Rev. B 45, 6564 (1992).

${ }^{31}$ M. Nakamura and Y. Misawa, J. Appl. Phys. 68, 1005 (1990).

${ }^{32}$ P. V. Santos and W. B. Jackson, Phys. Rev. B 46, 4595 (1992). 
${ }^{33}$ A. E. Widmer, R. Fehlmann, and C. W. Magee, J. Non-Cryst. Solids 54, 199 (1983).

${ }^{34}$ U. K. Das, T. Yasuda, and S. Yamasaki, Phys. Rev. Lett. 85, 2324 (2000).

${ }^{35}$ U. K. Das, T. Yasuda, and S. Yamasaki, Phys. Rev. B 63, 245204 (2001).

${ }^{36}$ S. Yamasaki, U. K. Das, and K. Ishikawa, Thin Solid Films 407, 139 (2002).

${ }^{37}$ I. M. P. Aarts, B. Hoex, A. H. M. Smets, R. Engeln, W. M. M. Kessels, and M. C. M. van de Sanden, Appl. Phys. Lett. 84, 3079 (2004).

${ }^{38}$ I. M. P. Aarts, A. C. R. Pipino, M. C. M. V. de Sanden, and W. M. M. Kessels, Appl. Phys. Lett. 90, 161918 (2007).

${ }^{39}$ W. B. Jackson, D. K. Biegelsen, R. J. Nemanich, and J. C. Knights, Appl. Phys. Lett. 42, 105 (1983).

${ }^{40}$ A. H. M. Smets, J. H. van Helden, and M. C. M. van de Sanden, J. NonCryst. Solids 299, 610 (2002).

${ }^{41}$ A. C. R. Pipino, Appl. Opt. 39, 1449 (2000).

${ }^{42}$ I. M. P. Aarts, A. C. R. Pipino, J. P. M. Hoefnagels, W. M. M. Kessels, and M. C. M. van de Sanden, Phys. Rev. Lett. 95, 166104 (2005).

${ }^{43}$ K. G. Tschersich and V. von Bonin, J. Appl. Phys. 84, 4065 (1998).

${ }^{44}$ K. G. Tschersich, J. Appl. Phys. 87, 2565 (2000).

${ }^{45}$ Y. J. Chabal and C. K. Patel, Physica B 126, 461 (1984).

${ }^{46}$ J. P. M. Hoefnagels, "A novel diagnostic approach for studying silicon thin film growth," Ph.D. thesis (Eindhoven University of Technology, 2005).

${ }^{47}$ P. J. van den Oever, J. J. H. Gielis, M. C. M. V. de Sanden, and W. M. M. Kessels, Thin Solid Films 516, 511 (2008).

${ }^{48}$ A. Gallagher, Thin Solid Films 395, 25 (2001).

${ }^{49}$ E. C. Molenbroek, A. H. Mahan, and A. Gallagher, J. Appl. Phys. 82, 1909 (1997).

${ }^{50} \mathrm{~W}$. Zheng and A. Gallagher, Thin Solid Films 501, 21 (2006).

${ }^{51}$ A. H. M. Smets and M. C. M. van de Sanden, Phys. Rev. B 76, 073202 (2007).

${ }^{52}$ K. Ohta and H. Ishida, Appl. Opt. 29, 1952 (1990).

${ }^{53}$ N. Wyrsch, F. Finger, T. J. Mcmahon, and M. Vanecek, J. Non-Cryst. Solids 137, 347 (1991).

${ }^{54}$ P. Kisliuk, J. Phys. Chem. Solids 3, 95 (1957).
${ }^{55}$ A. von Keudell and J. R. Abelson, Appl. Phys. Lett. 71, 3832 (1997).

${ }^{56}$ A. von Keudell and J. R. Abelson, J. Appl. Phys. 84, 489 (1998).

${ }^{57}$ A. von Keudell and J. R. Abelson, Phys. Rev. B 59, 5791 (1999).

${ }^{58}$ C. G. Van de Walle and R. A. Street, Phys. Rev. B 51, 10615 (1995).

${ }^{59}$ R. Darwich, P. Roca i Cabarrocas, S. Vallon, R. Osikovski, P. Morin, and K. Zellama, Philos. Mag. B 72, 363 (1995).

${ }^{60}$ W. E. Carlos and P. C. Taylor, Phys. Rev. B 25, 1435 (1982).

${ }^{61}$ R. E. Norberg, D. J. Leopold, P. A. Fedders, R. Borzi, P. H. Chan, J. Herberg, and N. Tomic, Mater. Res. Soc. Proc. 609, 475 (2000).

${ }^{62}$ U. Hansen and P. Vogl, Phys. Rev. B 57, 13295 (1998).

${ }^{63} \mathrm{~W}$. Beyer and U. Zastrow, J. Non-Cryst. Solids 266-269, 206 (2000).

${ }^{64}$ W. Beyer, Sol. Energy Mater. Sol. Cells 78, 235 (2003).

${ }^{65}$ J. Biener, C. Lutterloh, M. Wicklein, A. Dinger, and J. Küppers, J. Vac. Sci. Technol., A 21, 831 (2003).

${ }^{66}$ H. M. Branz, S. Asher, B. P. Nelson, and M. Kemp, J. Non-Cryst. Solids 164-166, 269 (1993).

${ }^{67}$ A. Van Wieringen and N. Warmoltz, Physica 22, 849 (1956).

${ }^{68}$ C. G. Van de Walle, P. J. H. Denteneer, Y. Baryam, and S. T. Pantelides, Phys. Rev. B 39, 10791 (1989).

${ }^{69}$ F. Kail, A. Fontcuberta i Morral, A. Hadjadj, P. Roca i Cabarrocas, and A. Beorchia, Philos. Mag. 84, 595 (2003).

${ }^{70}$ N. H. Nickel, W. B. Jackson, and J. Walker, Phys. Rev. B 53, 7750 (1996).

${ }^{71}$ M. Kemp and H. M. Branz, Phys. Rev. B 52, 13946 (1995).

${ }^{72}$ C. H. Seager and R. A. Anderson, Appl. Phys. Lett. 53, 1181 (1988).

${ }^{73}$ Private communication (21 December 2011).

${ }^{74}$ H. M. Branz, Phys. Rev. B 59, 5498 (1999).

${ }^{75}$ A. Fontcuberta i Morral, J. Bertomeu, and P. R. I. Cabarrocas, Mater. Sci. Eng., B 69-70, 559 (2000).

${ }^{76}$ H. M. Branz, Phys. Rev. B 60, 7725 (1999).

${ }^{77}$ S. Sriraman, S. Agarwal, E. S. Aydil, and D. Maroudas, Nature 418, 62 (2002).

${ }^{78}$ S. Sriraman, M. S. Valipa, E. S. Aydil, and D. Maroudas, J. Appl. Phys. 100, 053514 (2006).

${ }^{79}$ M. S. Valipa, S. Sriraman, E. S. Aydil, and D. Maroudas, J. Appl. Phys. 100, 053515 (2006) 